\title{
Wisdom from Experience Paradox: Organizational Learning, Mistakes, Hierarchy and Maturity Issues
}

\author{
Wioleta Kucharska \\ Gdansk University of Technology, Gdansk, Poland \\ wioleta.kucharska@pg.edu.pl
}

\begin{abstract}
Organisations often perceive mistakes as indicators of negligence and low performance, yet they can be a precious learning resource. However, organisations cannot learn from mistakes if they have not accepted them. This study aimed to explore how organisational hierarchy and maturity levels influence the relationship between mistakes acceptance and the ability to change. A sample composed of 380 Polish employees working in knowledge-driven organisations across various industries was used to examine this phenomenon. Data collection occurred from November to December 2019. Data were analysed through OLS regression, using PROCESS software. The findings revealed that the acceptance of mistakes positively influences adaptability to change. Moreover, because of mistakes acceptance, knowledge workers in organisations with a low-level hierarchy adapt to changes more effectively than those who work in strongly (or high-level) hierarchical companies. Additionally, higher levels of hierarchy result in lower adaptability to change, which is particularly visible in mature organisations. The study's essence is the empirical proof that a high level of organizational maturity and hierarchy can be a blocker of the adaptability to change if the organisation stays on the single-loop of learning (does perfectly what it used to do). Mistakes acceptance and thanks to this, also learning from mistakes, supports organisational change adaptability. Change adaptability is vital for double-loop learning (organizational actions re-framing). Moreover, this study has exposed the paradox of 'wisdom from experience' empirically. Namely, it is expected that experience and maturity result in positive outcomes and increased organisational leverage. Whereas more prominent, experienced, and mature organisations face serious difficulties when changing their routines and behaviours.
\end{abstract}

Keywords: constant learning culture, hierarchy, maturity, mistakes acceptance, change adaptability, organisational learning, single-loop learning, double-loop learning, knowledge workers

\section{Introduction}

Change is not only a key characteristic of today's business environment; it is also a major outcome of learning. 'Learning rarely happens without mistakes' (Downs, 1971, p. 1). That is why making mistakes can foster adaptability to change. When we learn, we change our perception of things through this extended knowledge. This should apply to both individuals and organisations. Organisational learning and change are interconnected (Argyris, 1982; Watad, 2019). Nadim and Singh (2019) noted that change, as a phenomenon, is tied to continuous learning. Garvin, et al. (2008) stressed that a learning organisation is characterised by openness to change when needed. Errors are the essence of organisational learning (Zappa and Robins, 2016). Moreover, Klingenberg and Rothberg (2020) have called for sustainable knowledge. Learning from mistakes can be a very promising action that supports the sustainability of knowledge processes. Mistakes, as a common human experience, can be a sustainable source of learning. There is no knowledge without learning, more effective learning results in more effective adaptability. Hence, it is beneficial to know how many mistakes are accepted by companies, as a first step in learning from mistakes and facilitating adaptability to change as a part of organisational learning routines.

Organisational learning is a process of identifying and modifying mistakes that have resulted from interactions between co-workers (Argyris and Schön 1997). Organisational hierarchy reflects the structure of relations that determine formal interactions between employees. Thus, it is vital to know how hierarchy influences the organisational ability to adapt to change through mistakes acceptance, as a part of organisational learning. Peter Senge (2006) claimed that if people want to learn, they must be ready to be wrong. The value of learning via mistakes is also highlighted by Anselmann and Mulder (2018). Yet 'learning from mistakes' seems more like a popular slogan than a popular attitude. Mistakes are controversial. The essence of this mistakes' paradox is that we cannot learn without making them, but they are never welcome. They can be useful for those who want to learn. This is why the mistakes acceptance factor in a learning culture is so vital. Without accepting mistakes, we cannot learn from them. Additionally, there is the problem of mistakes denial. Kalender, et al. (2020) and Anderson and Abrahamson (2017) - similarly to Zhao and Olivera (2006)-noted that a critical problem of organisational learning from mistakes is the lack of reporting. Mistakes denial, and trivialization might block the groupthink and knowledge creation (Mnasri and Papakonstantinidis, 2020). Therefore, this study compares the influence of mistakes acceptance on adaptability to change across industries, in the context of organisational 
maturity and hierarchy levels. To do this, the study starts with the conceptual framework and the method presentation. The results are then described and discussed. The limitations and implications of the research precede the conclusion.

\section{Conceptual framework}

Errors, mistakes and failure-these terms refer to actions whose final effect is unintended. Industry perceptions often determine different approaches to perceiving, defining, and managing mistakes. In production management, errors are associated with deviation from a specific norm; therefore, this term is often used in error management studies concerned with production (Seifried and Hopfer, 2013; Seckler, et al., 2017; Love, et al., 2018; Yao et al., 2021). Mistakes are usually associated with a wrong decision (Mangels et al., 2006). The concept of failure is often linked to the desired result of a significant undertaking not being achieved. The failure may have resulted from avoidable mistakes or from the unavoidable and negative results of risks undertaken, such as through experiments or new venture creations (Cannon and Edmonson, 2001; Politis and Gabrielsson, 2009). Therefore, errors, mistakes and failures can be caused equally by negligence or diligence (when acting under uncertain conditions). These situations can be characteristic of organisations in their early stages (e.g. start-ups), or mature organisations creating new business opportunities and adapting to constant changes in the business environment. Positive examples of learning from mistakes come from entrepreneurship studies, especially in relation to entrepreneurial learning from business failures (e.g., McGrath, 1999; Shepherd, 2003; Politis and Gabrielsson, 2009; Cope, 2011; Cardon, et al., 2011; Eggers and Song, 2015). An interesting background for the current study's aims is provided by the latest studies of failure in change management (e.g., De Keyser et al., 2021; Vardaman et al., 2021; Heracleous and Bartunek, 2021). These studies, and all examples given in the introduction, confirm that mistakes and change implementation are interrelated. Therefore, considering the current organisational demands for adapting to change, alongside the necessity of organisational learning for company growth, this study provides an in-depth exploration of these relationships. Specifically, this study explores how organisational hierarchy and maturity levels influence the relationship between mistakes acceptance and organisational ability to change.

\subsection{Organisational learning and change adaptability}

Mistakes might be a great source of learning (Kucharska, 2021). However, mistakes are surrounded by controversy, this topic is not a popular one. Some organisations want to be known as 'learning organisations', but they often exclude an employee's right to make mistakes. Husted and Michailova (2002) noted many uncertainties that encourage managers and other employees to put mistakes into the 'shadows'. This uncertainty is related to many elements, including colleagues' reactions to failure, the perceived risk of negative career consequences that discourages people from admitting to mistakes, the risk that failure may result in financial penalties, and the general uncertainty regarding cultural acceptance of mistakes and possible hostility towards those who make them. Lee, Peterson and Tiedens (2004), aligning with Heider's (1958) attribution theory, stressed that managers prefer to associate themselves with success rather than failure. As a result, mistakes are not exposed, discussed, or accepted, despite the positive learning outcomes that may arise. Watkins and Marsick (1993) noted that the first step in building a learning organisation is to create the ability to learn and change. Argyris and Schön (1997), Senge (2006), Garvin et al. (2008), and Rebelo and Gomes (2011; 2017) also highlighted that a learning culture must include acceptance of mistakes. This enables people to leave their comfort zones and solve problems by developing new approaches. Hind and Koenigsberger (2008) and Thomas and Brown (2011) argue similarly and have also stressed that higher levels of mistakes acceptance foster a learning process that is visible in the effective adoption of inevitable change. Mainga (2017), Kucharska and Bedford (2020a) argue that a consistent learning culture should not comprise just a learning-based environment but should also incorporate the acceptance of mistakes. Based on the outlined scholarship, the following hypothesis has been developed:

H1: Acceptance of mistakes influences adaptability to change positively.

\subsection{Moderators}

To explore the relationship between mistakes acceptance and the ability to change, it is vital to consider specific conditions that might moderate it. Moderators are vital to conditional processes examination. Specifically, a moderator is represented by a variable that explains the conditions under which a particular, examined causal effect occurs. Moreover, a moderator is a factor thanks to which the mentioned causal effect can be the subject of change. This is why moderated effects examination is vital for scientific development (Hayes, 2018). The current paper aims to verify how organisational maturity and hierarchy levels moderate adaptability to change, 
driven by learning through accepting mistakes. Namely, the effect of learning through accepting mistakes on organisational adaptability to change is interesting in the case if both factors occur simultaneously. Figure 1 presents the study's idea graphically. A justification for the imputation of both nominated moderators is outlined in the following section.

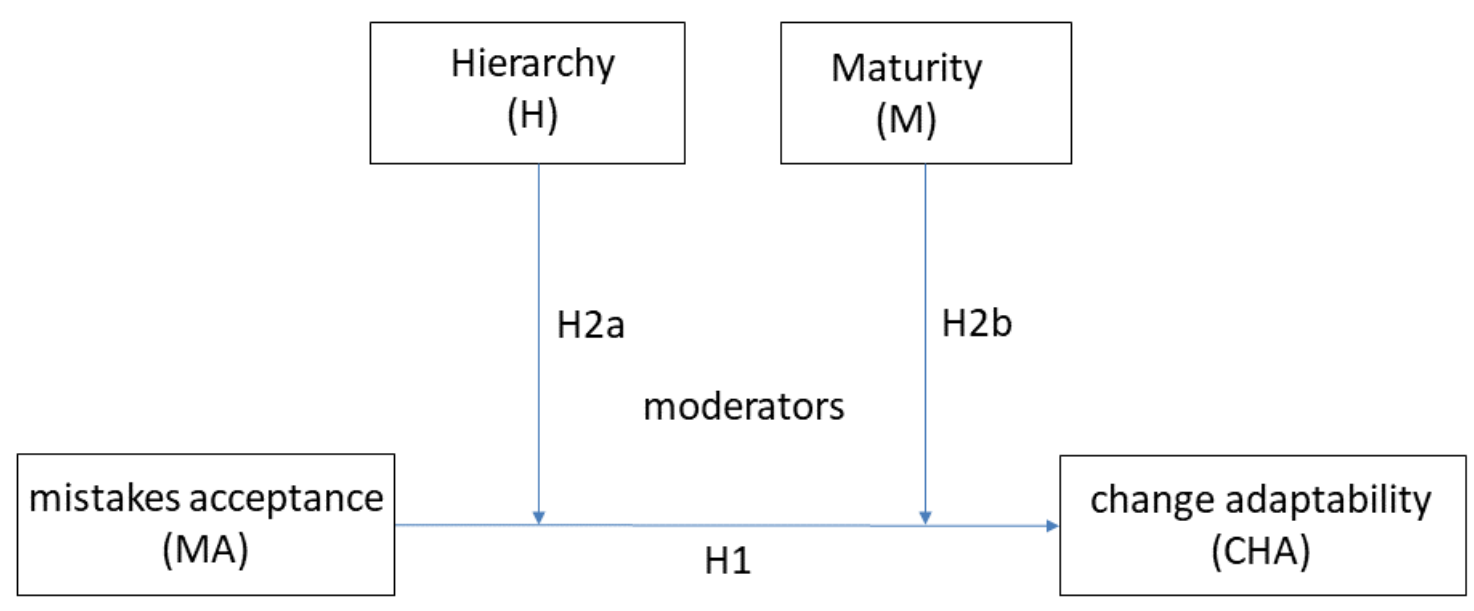

Figure 1: Theoretical framework

\subsubsection{Organisational hierarchy}

Post-bureaucratic organisations are characterised by a culture of learning and continual reflection that promotes organisational flexibility and responsiveness, dialogue, and consensus rather than formal authority and hierarchy (Harris and Hopfl, 2006; Laloux, 2014; Lee and Edmondson, 2017). Company culture matters for change adaptability and management (Baek et al., 2019; Brandt et al., 2019). Cameron and Quinn (1999) offered an organisational culture taxonomy that considers the following orthogonal organisational dimensions: 'flexibility and discretion' versus 'stability and control' and 'internal focus and integration' versus 'external focus and differentiation'. Next to a clan, adhocracy and market culture, the authors also identified a culture based on a hierarchy characterised by internal focus and integration, along with stability and control. In these organisations, employees are expected to strictly follow formal rules and policies, and adhere to their assigned positions, roles, and responsibilities. Security, conformity, predictability, stability, permanence, and deference to authority are desired. In a hierarchical environment, success is measured by dependability, efficiency, and cost-cutting.

A hierarchy is a complex dynamic that incorporates both vertical and horizontal organising practices. The vertical draws on and reproduces a formal organisation, whereas the horizontal orders people based on their knowledge and initiatives (Lundholm et al., 2010). Hierarchical dynamics depend on the social and epistemic distance of formal managers from operative work processes. Hence, it is worth knowing how a hierarchy (low- or high-level) may influence and moderate the adaptability to change via the acceptance of mistakes.

Moreover, Avent-Holt, et al. (2020) have noted that workplace occupations and positions often form the backbone of social stratification systems, providing a basic structure into which social resources flow. They form a fundamental variable in the social sciences for determining an individual's life chance. These authors also note that workplace hierarchies are more influential than national hierarchies because they constitute the local spaces within which individuals live and work together. The negative effects of being placed low in a hierarchy occur through everyday social interactions and relationships. Therefore, a local hierarchy can affect people's wellbeing more than a national one (according to the overall perceived positioning of a particular job). Hence, the hierarchy factor is significant. According to Parker (2012) and Vijayakumar and Padma (2014), hierarchy is a relevant factor that affects organisational learning, and it may also influence change (Kellogg et al., 2006; Barmby, et al., 2012; Turco, 2016). Hence, the following hypothesis has been developed:

H2a: The level of hierarchy moderates the relationship between mistakes acceptance and adaptability to change.

\subsubsection{Organisational maturity}

Organisational maturity is reflected in the implementation level of managerial and operational processes and systems that align with organisational aims (Verweire and Van Den Berghe, 2004; Albu and Panzar, 2010). 
Moreover, Verweire and Van Den Berghe (2004) claim that a misalignment between maturity and aim is a key reason behind the failure of many change initiatives. Therefore, an organisation's maturity level also appears vital to the relationship between mistakes acceptance and change adaptability. An organisation's maturity level, combined with its experience, should be advantageous to its business performance (Mullaly, 2014). The latest studies (e.g., Uskarci and Demirors, 2017; Andreasen and Gammelgaard, 2018; Grossman, 2018; Muszynska, 2018; Johansson et al., 2019; Marques, et al., 2019), along with most existing organisational maturity models (e.g. Paulk, 1993; Fischer, 2004; Harmon, 2004; Rosemann and de Bruin, 2005; Gunsberg, et al., 2018) include organisational maturity indicators such as communication and knowledge management levels, technology development and processes that-if constantly optimised-enable organisations to grow. Accordingly, an organisation's maturity level reflects its intra-organisational advancement. Therefore, it is vital to verify whether maturity levels, as well as the hierarchy model, moderate the relationship between mistakes acceptance and change adaptability. Figure 1 visualises the theoretical assumptions outlined here.

Hence, the following hypothesis has been developed:

$\mathrm{H} 2 \mathrm{~b}$ : Maturity moderates the relationship between mistakes acceptance and adaptability to change

\section{Method}

This study used a sample of 380 cases. Data collection occurred from November to December 2019. Data were analysed with ordinary least squares (OLS) regression, using PROCESS software. Respondents were recruited from Polish employees working in knowledge-driven organisations across industries, via a research panel recruited by answeo.com (see Appendix A). Only knowledge workers employed for a minimum of one year in a single company met the qualification criteria. As a result of this qualification process, most sample participants are male (50\%), aged 25 to 34 years $(43 \%)$, working in small and medium companies $(56 \%)$ in the information technology $(30 \%)$, sales $(12 \%)$, finance $(11 \%)$ and production $(9 \%)$ industries.

The study questionnaire began with a short introduction presenting the study's purpose. All terms were defined to ensure participant understanding of the questions. To measure mistakes acceptance and change adaptability, participants responded to statements using a 7-point Likert scale (adapted from Kucharska and Bedford, 2020a). Next, composite variables were created to apply the measures to the OLS regression analysis. A company's maturity was measured by applying Verweire and Van Den Berghe's (2004) 4-level criterion (start, low, medium, and high maturity level), using respondents' assessments of this in organisations, and linking this with the duration of an organisation's existence. The same 4-level assessment was applied to measure the hierarchy (extremely low, low, medium, high). To verify the sample quality, total sample variance was extracted at the $72 \%$ level; a Kaiser-Meyer-Olkin test of the sample's adequacy at 0.81 confirmed the sample's good quality (Cerny and Kaiser, 1977; Hair, et al., 2010). Furthermore, a Harman single-factor test (Podsakoff and Organ, 1986) was run. A result of $35 \%$ confirmed no bias was present. After this positive assessment of sample quality and scale reliability and validity (see Appendix B), composite variables were created to analyse the relationships hypothesised above, using the OLS regression PROCESS procedure for SPSS Version 3.4 (Hayes, 2018).

Bearing in mind the study aim, namely, exploring how organizational hierarchy and maturity levels influence the relationship between mistakes acceptance and change, OLS regression seems sufficient. Specifically, OLS regression adapts the least-squares criterion (a measure of the accuracy of a straight line in depicting the data that was used to generate it) to create multiple linear causal effects. As a result, the best fitting model to the data set is calculated to present the power of ties of expected causal effects. Consequently, in this study, based on the collected data set, it is measured how simultaneously hierarchy $(\mathrm{H})$ and maturity $(\mathrm{M})$ affect the causal relation of change adaptability (CHA) driven by mistakes acceptance (MA). In other words, how the effect between these two (CHA-MA) depends on the hierarchy $(\mathrm{H})$ and maturity $(\mathrm{M})$ factors -simultaneously.

\section{Results}

First, the fundamental hypothesis $(\mathrm{H} 1)$ of this research-namely, that mistakes acceptance supports change adaptability-is confirmed because of the direct relationship between the effect of mistakes acceptance on change adaptability. However, this study also explored how organisational hierarchy and maturity levels influence the relationship between mistakes acceptance and an organisation's ability to change. Therefore, the moderated effects of maturity and hierarchy factors were first examined separately and then simultaneously (with both moderators' imputations). The results show that separately, each moderator is significant. When analysed simultaneously, the total effect of both remains significant, but the moderated power was transferred 
to the maturity factor. Namely, the maturity-moderated effect was strengthened, whereas the hierarchy factor was not significant when moderators were analysed simultaneously. However, the moderated effect of both is significant. This means that to understand the explored phenomena in greater depth, both moderators are needed. Moreover, both factors are important, but the maturity level is critical. To clarify these results, Figure $2 \mathrm{a}$ visualises the hierarchy-moderated effect $(\mathrm{H} 2 \mathrm{a})$, Figure $2 \mathrm{~b}$ visualises maturity $(\mathrm{H} 2 \mathrm{~b})$, and Figure $2 \mathrm{c}$ visualises both. Appendices C, D, and E present the measurement details. Table 1 presents the hypothesis verification.

Table 1: Hypotheses verification

\begin{tabular}{|l|l|l|l|l|l|}
\hline \multicolumn{2}{|l|}{ Hypothesis } & $\beta$ & t-value & p-value & Hypothesis verification \\
\hline $\mathrm{H} 1$ & MA- > CHA & .34 & 3.37 & $* * *$ & supported \\
\hline $\mathrm{H} 2 \mathrm{a}$ & $\begin{array}{l}\text { hierarchy moderation on MA- }>\text { CHA } \\
\left(\mathrm{MA}^{\mathrm{x}} \mathrm{H}\right)\end{array}$ & .10 & 2.94 & $* *$ & supported \\
\hline $\mathrm{H} 2 \mathrm{~b}$ & \begin{tabular}{l} 
maturity moderation on MA- > CHA $\left._{(\mathrm{MA}} \mathrm{M}\right)$ \\
\hline
\end{tabular} & .08 & 2.34 & $*$ & supported \\
\hline
\end{tabular}

Note: $\mathrm{n}=380^{*} \mathrm{p}<.05^{* *} \mathrm{p}<.01^{* * *} \mathrm{p}<.001$. Standardised coefficients are not available for models with moderators; levels of confidence for all confidence intervals in the output: 95.0000; PROCESS procedure for SPSS Version 3.4 output details available in Appendices D \& E.

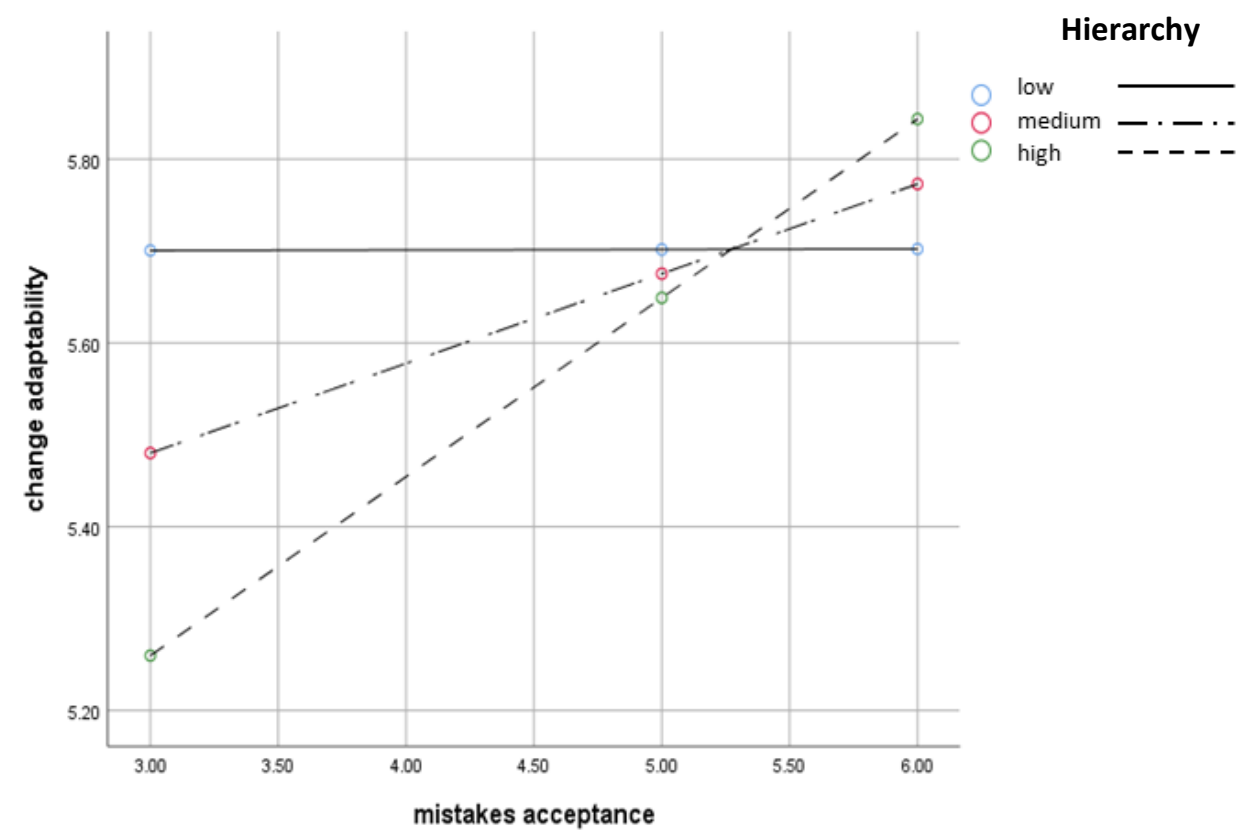

Figure 2a: Moderated effect of hierarchy level on change adaptability driven by mistakes acceptance

Note: level of confidence for all confidence intervals in the output: 95.0000; values low, medium, high reflect the 16th, 50th, and 84th percentiles; effects not standardized. Source: Kucharska and Bedford (2020b). 


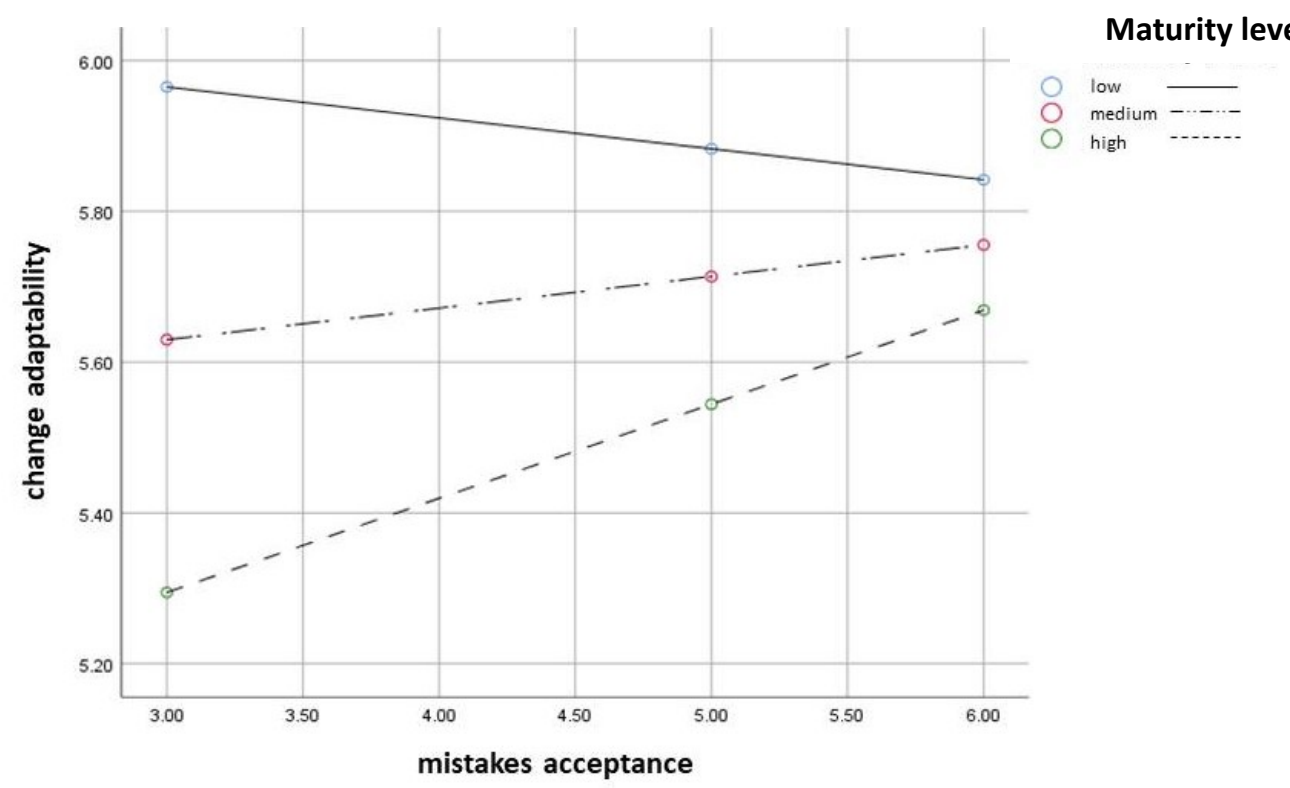

Figure 2b: Moderated effect of maturity level on change adaptability driven by mistakes acceptance

Note: level of confidence for all confidence intervals in the output: 95.0000; values low, medium, high reflect the 16th, 50th, and 84th percentiles; effects not standardized. Source: Kucharska and Bedford (2020c).

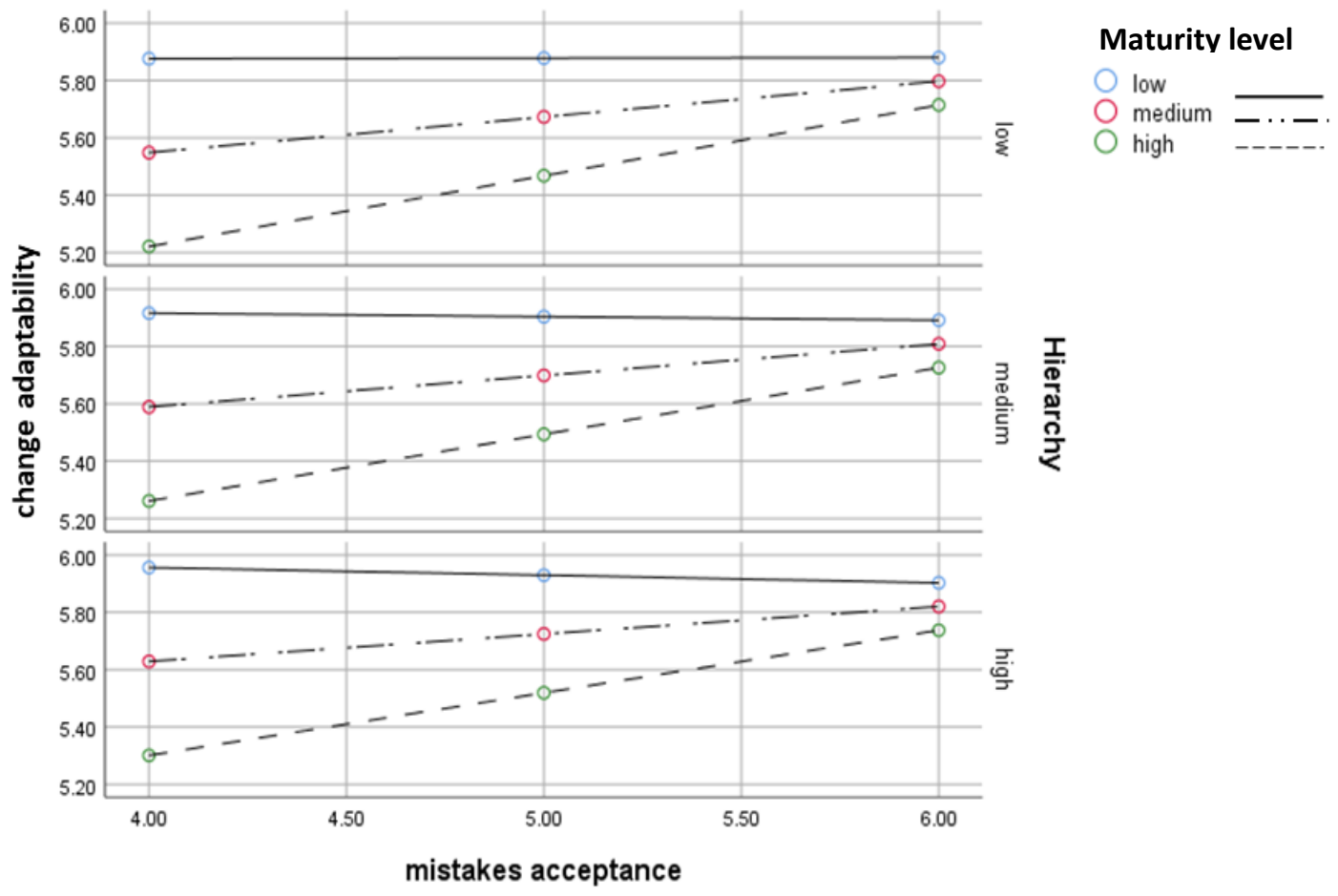

Figure 2c: Moderated effect of hierarchy and maturity level on change adaptability driven simultaneously by maturity and mistakes acceptance

Note: level of confidence for all confidence intervals in the output: 95.0000; values low, medium, high reflect the 16th, 50th, and 84th percentiles; effects not standardised.

Figure 2c visualises the details of the hierarchy and maturity effects simultaneously. In addition, the simultaneous moderated effect is only significant for medium and high levels of maturity and hierarchy (see conditional effects of the focal predictor at values of the moderators in Appendix C). Consequently, it is apparent that a low-level hierarchy working environment is characterised by high adaptability to change; however, the mistakes acceptance level does not influence the adaptability to change at all. Thus, the relationship between mistakes acceptance and change adaptability remains unchanged, and so is not significant for this relationship. For medium- and high-level hierarchies and maturity levels, the positive effect of mistakes acceptance on change 
adaptability is significant, but it is stronger in less mature organisations. Namely, a more mature organisation will have a lower effect of change adaptability improvements that result from accepting mistakes. Furthermore, for organisations with high levels of hierarchy, the influence of mistakes acceptance on adaptability to change is more substantial. Notably, employees working in organisations with lower hierarchy levels adapt to change more effectively than those working under higher levels of hierarchy. However, when highly hierarchical, mature organisations accept mistakes, they can achieve greater adaptability to change than organisations with low- and medium-level hierarchies.

\section{Discussion}

From the results described above, it might be concluded that employees working in low-level hierarchy organisations adapt to change much better than those in strongly hierarchical companies. Regarding mistakes, accepting them improves the adaptability to change significantly. Therefore, high-level hierarchy organisations that accept mistakes achieve better results in relation to adaptability to change than do low- and mediumhierarchy organisations. However, the lower an organisation's hierarchy level, the lower the significance of mistakes acceptance will be for adaptability to change (and it appears to not be significant at all). Hence, the conclusion is that strongly hierarchical organisations may adapt to change only if they accept errors. However, this is only true if the mistakes acceptance level is high (see Figure 2a). When this acceptance is low, a strongly hierarchical organisation's adaptability to change will also be very low.

The analysis of an organisation's maturity level-moderated effects on mistakes acceptance (see Figure 2b) and change adaptability has revealed that the higher an organisation's maturity level, the lower their change adaptability will be, even if mistakes acceptance is high. In the light of Organizational Learning Theory (Argyris, 1976, Argyris and Schon, 1996), the findings suggest that organisations, even if they do learn from mistakes, do so at the single-loop level (i.e. they improve standard acting) (Argyris, 1976, p. 367). If mature organisations with well-developed processes and policies learn from mistakes, they do so by modifying actions and maintaining their existing rules. In other words, they learn to operate more effectively, but do not question the fundamental aspects of their organisational design. To do so would incorporate what Argyris has termed a higher-level double-loop of organisational trial-error learning (Argyris 1976, p. 367). Therefore, the observed levels of adaptability to change in mature organisations are lower than those observed in less mature organisations. More mature organisations have lower adaptability to change, and this is especially visible for strongly hierarchised organisations (see Figure 2c). They are good at standard acting improvement but have problems with adaptation and re-framing. In the light of the presented findings, learning from mistakes supports organizational change adaptability even when the hierarchy is high, which is vital for double-loop learning (organisational actions reframing). It can be explained by the common problem of high hierarchical organizations where the "boss never makes mistakes and does not accept them." In such organizations, everybody naturally avoids them, but if they happen, hide them to avoid a negative judgment. Kalender et al. (2020), Anderson and Abrahamson (2017), similarly to Zhao and Olivera (2006), noted that the critical problem of organizational learning from mistakes is lack of reporting. Therefore, they highlighted the need for organizations to change their attitude towards errors. Based on Ferguson (2017), Zabari and Southern (2018), and Robertson and Long (2018), the error reporting problem might stem from the organizational "culture of blame and shame." If the mistakes stay hidden, they cannot be a lesson for anybody except the person who made them. Presented findings revealed that if highly hierarchical organizations accept mistakes and learn from them, they adapt to change better. Thus, mistake acceptance supports double-loop learning.

This study has exposed the paradox of 'wisdom from experience' empirically. It is expected that experience and maturity result in positive outcomes and increased organisational leverage, similarly to the effect that experience and maturity has on individuals (Saint-Onge, 1996). However, in the context of organisational innovativeness, things are not this simple. Goncalves, et al. (2020) highlighted that smaller and less experienced organisations (specifically, start-ups) are flexible, fast, more agile, and more innovative than larger and betterresourced organisations. Thus, more prominent, experienced, and mature organisations experience more difficulties when changing their routines and behaviours.

\section{Limitations and implications}

The most important limitation of this study is that mistakes acceptance is treated as a proxy for learning from mistakes. Acceptance of mistakes does not equate to learning from mistakes, but without mistakes acceptance, learning from mistakes might be difficult or even impossible (Van Dyck et al., 2013). 
Moreover, another limitation worth discussing is that the current study links the measurement of a company's maturity level to the duration of its existence. Kumar, et al. (2013) proposed a more refined method that, if applied, may have led to more accurate results. Another limitation is that learning from mistakes is often an informal and therefore a subconscious phenomenon. Consequently, the low R-sq $=0.078$ obtained for the entire model (see Appendix C) is not surprising. Since the process is so specific, perhaps choosing a method other than the self-reported questionnaire would enhance further exploration of this problem.

Moreover, the findings demonstrate the importance of studies on mistakes acceptance by learning organisations. It is apparent that mistakes acceptance should be investigated in greater depth. The results of this study are based on a Polish sample; additional nationality-based studies are needed. As Kucharska (2021) noted, mistakes acceptance might be affected by a nation's culture. Therefore, national differences might exist in relation to learning from mistakes. Exploring this phenomenon more deeply could provide interesting directions for future studies.

Moreover, the applied data set is composed of cases gathered from different industries. Therefore, all presented findings are generalisations specific to Poland. Still, it is proved (Kucharska and Erickson, 2020) that because usually industries' business operation conditions vary considerably, it is worth exploring some phenomena from a cross-sector view. Therefore, for future research it would be beneficial to study in-depth the phenomenon in a specific sector context. The current data set is too small to present such cross-industry comparison keeping the scientific rigor. Therefore, further studies are needed.

\section{Practical implications}

The most important practical implication of the present study applies to mature organisations. An acceptance of mistakes would allow them to better adapt to change. Hence, mature organisations should create mechanisms that support learning from mistakes. As noted in the introduction, errors are commonly perceived as a phenomenon to be eliminated, and that is why employees often conceal their mistakes. Since everybody makes mistakes, and most people hide them, a kind of illusion is created. The study's findings encourage mature organisations to be responsible. They can do this by developing internal mechanisms that will take advantage of the mistakes employees make, transforming the mistakes into 'lessons learned'. Mistakes are a valuable source of new knowledge, which is important if we want to achieve better adaptability to change. Organisations with a low maturity level are characterised by a high level of change adaptability. This is because they develop mainly by adaptation to market rules and standards imposed by market leaders (mature organisations). If the low maturity level companies want to win a market share, they must set and maintain minimum standards and should aim to exceed these standards. This is why the effect of mistakes acceptance on less mature companies is opposite to the effect on mature organisations.

Based on the above, another important practical implication of the present study relates to managers. In consideration of the study's findings, managers should support employees in the process of learning from mistakes. This is because a strongly hierarchical organisation may adapt to changes in a significant manner only if the level of mistake acceptance is high. If they do not adapt, the organisational learning process is at risk. From a practical perspective, this is not always easy: organisations do not like accepting mistakes. This is one of the biggest paradoxes of 'learning organisations' today. The present findings also suggest that an effective manager working in a hierarchical learning organisation should be a training leader, coach and patient teacher, rather than a 'mistakes a hunter'. This is the challenge for managers working in learning organisations: to be someone who inspires, motivates, and supports learning. The issues of error, leading and learning to change were raised by Bligh et al. (2018) and Harvey et al. (2021).

\section{Conclusion}

This article, similarly to Kucharska and Bedford (2020a-c), exposes the paradox of ignoring mistakes by today's learning organisations. The findings show that mature organisations may adapt to change significantly better if they learn from mistakes. If companies do not accept mistakes, the observed adaptation levels are low. This explains why mature (often big and strongly hierarchical) organisations are slower to develop and less agile in their responses than non-hierarchical organisations. This study demonstrates that for less mature organisations to survive and advance in a particular industry, they must adapt quickly, and therefore must not allow mistakes to happen. On the other hand, mature organisations that have been around for a long time can only grow by learning from their errors, because they set the business standards for a branch of the industry, or an industry 
as a whole. The most significant player always dictates the terms to its followers. Of course, both less and more mature organisations must adapt to constant technological, societal, cultural, political, and other environmental changes if they want to grow. However, in the case of mature and experienced organisations, new errors may be a valuable symptom of something that has changed or is worth changing.

\section{References}

Albu, E. and Panzar, C. (2010), "A new tool for assessing maturity alignment: The enterprise maturity matrix", Performance Improvement, Vol. 49 Issue 9, pp. 35-47. https://doi.org/10.1002/pfi.20179

Anderson, J.G. and Abrahamson, K. (2017), "Your Health Care May Kill You: Medical Errors", Studies in Health Technology and Informatics, Vol. 234, pp. 13-17.

Andreasen, P.H. and Gammelgaard, B. (2018), "Change within purchasing and supply management organisations Assessing the claims from maturity models", Journal of Purchasing and Supply Management, Vol. 24 No. 2, pp. 151163. https://doi.org/10.1016/j.pursup.2017.11.005

Anselmann, V. and Mulder, R. (2018), "Learning from errors in insurance companies", Journal of Management Development, Vol. 37 No. 2, pp. 138-148. https://doi.org/10.1108/JMD-06-2017-0211

Argyris, C and Schön, DA (1996), Organizational Learning II: Theory, Method and Practice. Addison-Wesley, Massachusetts.

Argyris, C. (1982), How learning and reasoning processes affect organizational change, in Goodman, P.S. et al. (Eds), Change in Organizations. Jossey Bass, CA: San Francisco, pp. 47-86.

Argyris, C. and Schön, D.A. (1997), "Organizational learning: a theory of action perspective”, Reis, Vol. 77/78, pp. 345-348. https://doi.org/10.2307/40183951

Argyris, Ch. (1976), Increasing Leadership Effectiveness, Wiley-Interscience, New York, NY.

Avent-Holt, D., Halsten, M. and Cort, D. (2020), “Occupational status and organizations: Variation in occupational hierarchies across Swedish workplaces", Research in Social Stratification and Mobility. https://doi.org/10.1016/j.rssm.2019.100423

Baek, P., Chang, J. and Kim, T. (2019), "Organizational culture now and going forward", Journal of Organizational Change Management, Vol. 32 No. 6, pp. 650-668.

Barmby, T., Eberth, B. and Ma, A. (2012), "Incentives, learning, task difficulty, and the Peter Principle: Interpreting individual output changes in an Organisational Hierarchy", Labour Economics, Vol. 19, pp. 76-81.

Bligh, M., Kohles, J.C. and Yan, Q. (2018), "Leading and Learning to Change: The Role of Leadership Style and Mindset in Error Learning and Organizational Change", Journal of Change Management, Vol. 18, pp. 116-141.

Brandt, E.N., Andersson, A.-C. and Kjellstrom, S. (2019), "The future trip: a story of transformational change", Journal of Organizational Change Management, Vol. 32 No. 7, pp. 669-686. https://doi.org/10.1108/JOCM-09-2017-0358

Cameron, K.S. and Quinn, R.E. (1999), Diagnosing and Changing Organizational Culture: Based on the Competing Values Framework, Addison-Wesley, Reading, MA.

Cannon, M.D. and Edmondson, A.C. (2001), "Confronting failure: antecedents and consequences of shared beliefs about failure in organizational work groups", Journal of Organizational Behavior, Vol. 22 No. 2, pp. 161-177.

Cardon, M.S., Stevens, C.E. and Potter, D.R. (2011), "Misfortunes or mistakes?: Cultural sensemaking of entrepreneurial failure", Journal of Business Venturing, Vol. 26 No. 1, pp. 79-92.

Cerny, C.A. and Kaiser, H.F. (1977), "A study of a measure of sampling adequacy for factor-analytic correlation matrices", Multivariate Behavioral Research, Vol. 12 No. 1, pp. 43-47. https://doi.org/10.1207/s15327906mbr1201_3

Cope, J. (2011), "Entrepreneurial learning from failure: an interpretative phenomenological analysis", Journal of Business Venturing, Vol. 26 No. 6, pp. 604-623.

De Keyser, B., Guiette, A. and Vandenbempt, K. (2021), "On the dynamics of failure in organizational change: A dialectical perspective", Human Relations, Vol. 74, Issue2. https://doi.org/10.1177/0018726719884115

Downs, S. (1971), "Mistakes in learning: Effects on the older trainee", Industrial and Commercial Training, Vol. 3 No. 11, pp. 542-544.

Eggers, J.P. and Song, L. (2015), "Dealing with Failure: Serial Entrepreneurs and the Costs of Changing Industries Between Ventures", Academy of Management Journal, Vol. 58 No. 6, pp. 1785-1803.

Ferguson, C.C. (2017), "The Emotional Fallout From the Culture of Blame and Shame", JAMA pediatrics, Vol. 171 No. 12, pp. 1141.

Fischer, D.M. (2004), "The business process maturity model: a practical approach for identifying opportunities for optimization", available at: www.bpmg.orgwww.bptrends.com/publicationfiles/1004\%20ART\%20BP\%20Maturity\%20Model\%20-\%20Fisher.pdf [accessed December 15, 2019].

Garvin, D. A., Edmondson, A. C. and Gino, F. (2008), "Is yours a learning organization?”, Harvard Business Review, Vol. 86 No. 3, pp. 109.

Goncalves, D., Bergquist, M., Bunk, R. and Alänge, S. (2020), "Cultural aspects of organizational agility affecting digital innovation", Journal of Entrepreneurship, Management, and Innovation, Vol. 16 No. 4, pp. 13-46.

Grossman, R.L. (2018), “A framework for evaluating the analytic maturity of an organization”, International Journal of Information Management, Vol. 38 No. 1, pp. 45-51. https://doi.org/10.1016/j.ijinfomgt.2017.08.005

Gunsberg, D., Callow, B., Ryan, B., Suthers, J., Baker, P. and Richardson, J. (2018), “Applying an organisational agility maturity model", Journal of Organizational Change Management, Vol. 31 No. 6, pp. 1315-1343. https://doi.org/10.1108/JOCM-10-2017-0398 
Harmon, P. (2004), "Evaluating an organization"s business process maturity", Business Process Trends Newsletter, Vol. 2 No. 3, pp. 1-11.

Harris, M. and Hopfl, H. (2006), "Organizations in the Age of Post-Bureaucracy", Journal of Organization Change Management, Vol. 19 No. 1.

Harvey, W.S., Mitchell, V.-W., Almeida Jones, A. and Knight, E. (2021), "The tensions of defining and developing thought leadership within knowledge-intensive firms", Journal of Knowledge Management, Vol. 25 No. 11, pp. 133. https://doi.org/10.1108/JKM-06-2020-0431

Hayes, A. (2018), Introduction to mediation, moderation and conditional process analysis: A regression-based approach, New York, NY: Guilford Press.

Heider, F. (1958), The psychology of interpersonal relations, New York, NY: Wiley.

Heracleous, L. and Bartunek, J. (2021), "Organization change failure, deep structures and temporality: Appreciating Wonderland", Human Relations, Vol. 74 No. 2, pp. 208-233.

Hind, M. and Koenigsberger, J. (2008), "Culture and commitment: the key to the creation of an action learning organization", Action Learning: Research and Practice, Vol. 4 No. 1, pp. 87-94. https://doi.org/10.1080/14767330701233939

Husted, K. and Michailova, S. (2002), “Diagnosing and fighting knowledge-sharing hostility”. Organizational Dynamics, Vol. 31 No. 1, pp. 60-73.

Johansson, C., Grandien, Ch. and Strandh, K. (2019), "Roadmap for a communication maturity index for organizationsTheorizing, analyzing and developing communication value", Public Relations Review, Vol. 45 No. 4, pp. 101791. https://doi.org/10.1016/j.pubrev.2019.05.012

Kalender, Z.T., Tozan, H. and Vayvay, O. (2020), "Prioritization of Medical Errors in Patient Safety Management: Framework Using Interval-Valued Intuitionistic Fuzzy Sets", Healthcare (Basel), Vol. 8 No. 3, pp. 265.

Kellogg. K. C., Orlikowski, W. J. and Yates, J. (2006), "Life in the Trading Zone: Structuring Coordination Across Boundaries in Postbureaucratic Organizations", Organization Science, Vol. 17 No. 1, https://doi.org/10.1287/orsc.1050.0157

Klingenberg, B. and Rothberg, H.N. (2020), The Status quo of Knowledge Management and Sustainability Knowledge, Electronic Journal of Knowledge Management, Vol. 18 No. 2. https://doi.org/10.34190/EJKM.18.02.004

Kucharska, W. (2021), "Do mistakes acceptance foster innovation? Polish and US cross-country study of tacit knowledge sharing in IT", Journal of Knowledge Management. https://doi.org/10.1108/JKM-12-2020-0922

Kucharska, W. and Bedford, D.A.D. (2020a), "Love your mistakes!-They help you adapt to change. How do knowledge, collaboration, and learning culture foster organizational intelligence?', Journal of Organizational Change Management, Vol. 33 No.7, pp. 1329-1354. https://doi.org/10.1108/JOCM-02-2020-0052

Kucharska, W. and Bedford, D.A.D (2020b), "Learning from mistakes. A study on maturity and adaptability to change", Proceedings of 35th IBIMA Conference: Education Excellence and Innovation Management: A 2025 Vision to Sustain Economic Development during Global Challenges, pp. 1263-1271.

Kucharska, W. and Bedford, D.A.D. (2020c), The power of mistakes-constant learning culture and hierarchy. Proceedings of European Conference on Knowledge Management, Vol. 3, pp. 441-446.

Kucharska, W. and Erickson, G.S. (2020), "The influence of IT-competency dimensions on job satisfaction, knowledge sharing and performance across industries", VINE Journal of Information and Knowledge Management Systems, Vol. 50 No. 3, pp. 387-407.

Kumar, U., Parida, A., Duffuaa, S., Macchi, M. and Fumagalli, L. (2013), "A maintenance maturity assessment method for the manufacturing industry", Journal of Quality in Maintenance Engineering, Vol. 19 No. 3, pp. 295-315. https://doi.org/10.1108/JQME-05-2013-0027

Laloux, F. (2014), Reinventing organizations : a guide to creating organizations inspired by the next stage in human consciousness, Brussels : Nelson Parker.

Lee, F., Peterson, C. and Tiedens, L.Z. (2004), "Mea culpa: Predicting stock prices from organizational attributions", Personality and Social Psychology Bulletin, Vol. 30, pp. 1636-1649.

Lee, M.Y. and Edmondson, A.C. (2017), "Self-managing organizations: Exploring the limits of less-hierarchical organizing", Research in Organizational Behavior, Vol. 37, pp. 35-58.

Love, P.E.D., Smith, J. and Teo, P. (2018), "Putting into practice error management theory: Unlearning and learning to manage action errors in construction", Applied Ergonomics, Vol. 69, pp. 104-111.

Lundholm, S., Rennstam, J. and Alvesson, M. (2012), Understanding Hierarchy in Contemporary Work", "Bureaucracy and Hierarchy - what Else!?, in Diefenbach, T. and Todnem By, R. (Ed.) Reinventing Hierarchy and Bureaucracy - from the Bureau to Network Organizations (Research in the Sociology of Organizations, Vol. 35), Emerald Group Publishing Limited, Bingley, pp. 1-27. https://doi.org/10.1108/S0733-558X(2012)0000035003

Mangels, J.A., Butterfield, B., Lamb, J., Good, C. and Dweck, C.S. (2006), "Why do beliefs about intelligence influence learning success? A social cognitive neuroscience model", Social Cognitive and Affective Neuroscience, Vol. 1, Issue 2, September 2006, pp. 75-86. https://doi.org/10.1093/scan/nsl013

Mainga, W. (2017), "Examining project learning, project management competencies, and project efficiency in projectbased firms (PBFs)", International Journal of Managing Projects in Business, Vol. 10 No. 3, pp. 454-504. https://doi.org/10.1108/IJMPB-04-2016-0035

Marques, J., La Falce, J., Marques, F., De Muylder, C. and Silva, J. (2019), „The relationship between organizational commitment, knowledge transfer and knowledge management maturity", Journal of Knowledge Management, Vol. 23 No. 3, pp. 489-507. 
McGrath, R.G. (1999), "Falling forward: Real options reasoning and entrepreneurial failure", Academy of Management Review, Vol. 24 No. 1, pp. 13-30.

Mnasri, S. and Papakonstantinidis, S. (2020), "Detrivialization as a Strategy to Challenge Organizational Groupthink", Electronic Journal of Knowledge Management, Vol. 18 No. 3, pp. 224-235.

Mullaly, M. (2014), "If maturity is the answer, then exactly what was the question?", International Journal of Managing Projects in Business, Vol. 7 No. 2, pp. 169-185. https://doi.org/10.1108/IJMPB-09-2013-004

Muszynska, K. (2018), „Communication maturity model for organizations realizing EU projects”, Procedia Computer Science, Vol. 126, pp. 2184-2193.

Nadim, A. and Singh, P. (2019), “Leading change for success: embracing resistance”, European Business Review, Vol. 31 No. 4, pp. 512-523. https://doi.org/10.1108/EBR-06-2018-0119

Parker, M. (2012), Super Flat: Hierarchy, Culture and Dimensions of Organizing, in Diefenbach, T. and Todnem By, R. (Ed.) Reinventing Hierarchy and Bureaucracy - from the Bureau to Network Organizations (Research in the Sociology of Organizations, Vol. 35), Emerald Group Publishing Limited, Bingley, pp. 229-247.

Paulk, M.C., Curtis, B., Chrissis, M.B. and Weber, C.V. (1993), "Capability maturity model, version 1.1”, Software, IEEE, Vol. 10 No. 4, pp. 18-27.

Podsakoff, P.M. and Organ, D. (1986), "Self-reports in organizational research: problems and prospects", Journal of Management, Vol. 12 No. 4, pp. 531-544. https://doi.org/10.1177/014920638601200408

Politis, D. and Gabrielsson, J. (2009), "Entrepreneurs' attitudes towards failure: An experiential learning approach", International Journal of Entrepreneurial Behavior \& Research, Vol. 15 No. 4, pp. 364-383.

Rebelo, T. and Gomes, A.D. (2011), The OLC questionnaire: a measure to assess an organization's cultural orientation towards learning, in Mesquita, A. (Ed.) Technology for Creativity and Innovation: Tools, Techniques and Applications. Information Science References-Hershey, PA: IGI Global, pp. 216-236.

Rebelo, T. and Gomes, A.D. (2017), "Is organizational learning culture a good bet? An analysis of its impact on organizational profitability and customer satisfaction", Academia Revista Latinoamericana de Administración, Vol. 30 No. 3, pp. 328-343. https://doi.org/10.1108/ARLA-10-2015-0275

Robertson, J.J. and Long, B. (2018)," Suffering in Silence: Medical Error and its Impact on Health Care Providers", J Emerg Med, Vol. 54 No. 4, pp. 402-409. https://doi:10.1016/j.jemermed.2017.12.001

Rosemann, M. and de Bruin, T. (2005), "Towards a business process maturity model", European Congress on Information Systems, Regensburg.

Saint-Onge, H. (1996), "Tacit knowledge the key to the strategic alignment of intellectual capital", Planning Review, Vol. 24 No. 2, pp. 10-16. https://doi.org/10.1108/eb054547

Seckler, Ch., Gronewold, U. and Reihlen, M. (2017), "An error management perspective on audit quality: Toward a multilevel model", Accounting, Organizations and Society, Vol. 62, pp. 21-42.

Seifried, J. and Höpfer, E. (2013), "The Perception of Error in Production Plants of a Chemical Organisation", Vocations and Learning, Vol. 6, pp. 159-185.

Senge, P.M. (2006), The Fifth discipline. The Art \& Practice of the Learning Organization, NY: Crown Business.

Shepherd, D.A. (2003), "Learning from business failure: Propositions of grief recovery for the self-employed", Academy of Management Review, Vol. 28 No. 2, pp. 318-328.

Thomas, D. and Brown, J. S. (2011), A new culture of learning: Cultivating the imagination for a world of constant change, Lexington, Kentucky: CreateSpace.

Turco, C.J. (2016), The Conversational Firm: Rethinking Bureaucracy in the Age of Social Media, Columbia University Press.

Uskarci, A. and Demirirs, O. (2017), „Do staged maturity models result in organization-wide continuous process improvement? Insight from employees", Computer Standards \& Interfaces, Vol. 52, pp. 25-40. https://doi.org/10.1016/j.csi.2017.01.008

Van Dyck, C., Dimitrova, NG, De Korne, D.F. and Hiddema, F. (2013), "Walk the talk: leaders' enacted priority of safety, incident reporting, and error management", Leading in Health Care Organizations: Improving Safety, Satisfaction and Financial Performance, Vol. 14, pp. 95-117.

Vardaman, J.M., Amis, J.M., Wright, P.M. and Dyson, B.P. (2021), "Reframing childhood obesity: The role of local communities in change implementation failure", Human Relations, Vol. 74 No. 2, pp. 258-285.

Verweire, K. and Van Den Berghe, L. (Eds.). (2004), Integrated performance management: A guide to strategy implementation, Thousand Oaks, CA: Sage.

Vijayakumar, V. and Padma, R. (2014), "Impact of perceived organizational culture and learning on organizational identification", International Journal of Commerce and Management, Vol. 24 No. 1, pp. 40-62.

Watad, M. (2019), Organizational learning and change: Can they coexist? Business Process Management Journal, Vol. 25 No. 5, pp. 1070-1084. https://doi.org/10.1108/BPMJ-12-2016-0240

Watkins, K. and Marsick, V. (1993), Sculpting the learning organization, San Francisco, CA: Jossey-Bass.

Yao, K., Li, X. and Liang, B. (2021), "Failure learning and entrepreneurial resilience: the moderating role of firms' knowledge breadth and knowledge depth", Journal of Knowledge Management. https://doi.org/10.1108/JKM-10-2020-0772

Zabari, M.L. and Southern, N.L. (2018), "Effects of Shame and Guilt on Error Reporting Among Obstetric Clinicians", J Obstet Gynecol Neonatal Nurs, Vol. 47 No. 4, pp. 468-478. https://doi: 10.1016/j.jogn.2018.03.002

Zappa, P. and Robins, G. (2016), "Organizational learning across multi-level networks", Social Networks, Vol. 44, pp. 295306. https://doi.org/10.1016/j.socnet.2015.03.003

Zhao, B. and Olivera, F. (2006), "Error reporting in Organizations", Academy of Management Review, Vol. 31, No.4. 


\section{Appendices}

Appendix A: Description of samples

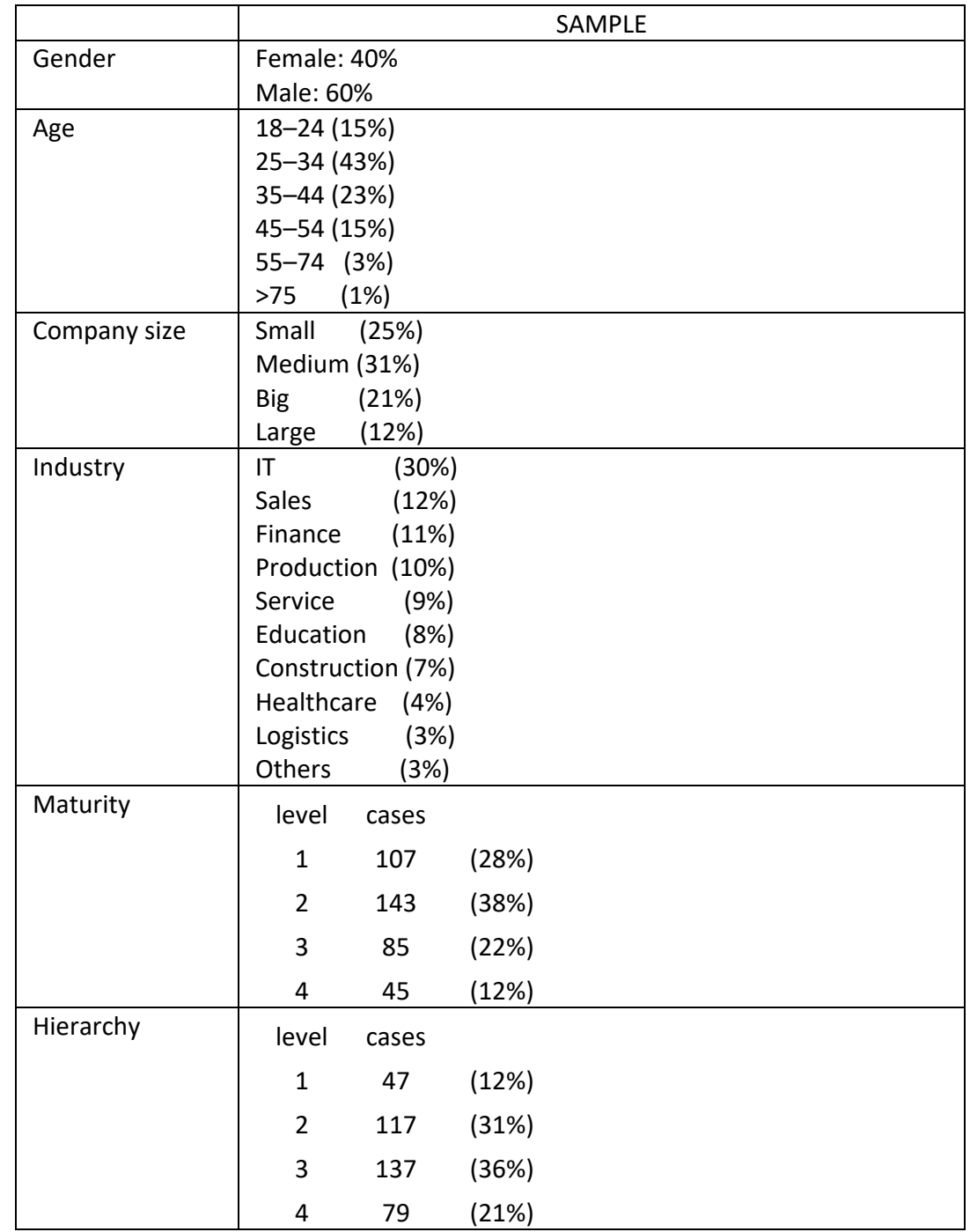

Appendix B: Scales

\begin{tabular}{|c|c|c|}
\hline Scale & $\begin{array}{c}\text { Composite variable } \\
\text { mean/S.D. }\end{array}$ & Reliability \\
\hline $\begin{array}{l}\text { "Mistakes acceptance" dimension of constant learning culture } \\
\text { (MA) } \\
\text { - people know that mistakes are a learning consequence } \\
\text { - most tolerate them to a certain point } \\
\text { - } \quad \text { we discuss problems openly without blaming } \\
\text { - mistakes are tolerated and treated as learning } \\
\text { opportunities } \\
\text { (Kucharska and Bedford, 2020a) }\end{array}$ & $5.13 / 1.42$ & $\begin{array}{l}\text { Cronbach } \\
\alpha=.85\end{array}$ \\
\hline $\begin{array}{c}\text { Personal change adaptability (CHA) } \\
\text { - I am flexible to changes } \\
\text { - I can adjust to changes } \\
\text { - I adapt to changes easily } \\
\text { - I am used to changes } \\
\text { (Kucharska and Bedford, 2020a) }\end{array}$ & $5.67 / 1.1$ & $\begin{array}{l}\text { Cronbach } \\
\alpha=.88\end{array}$ \\
\hline
\end{tabular}




\section{Appendix C: Process output}

Run MATRIX procedure:

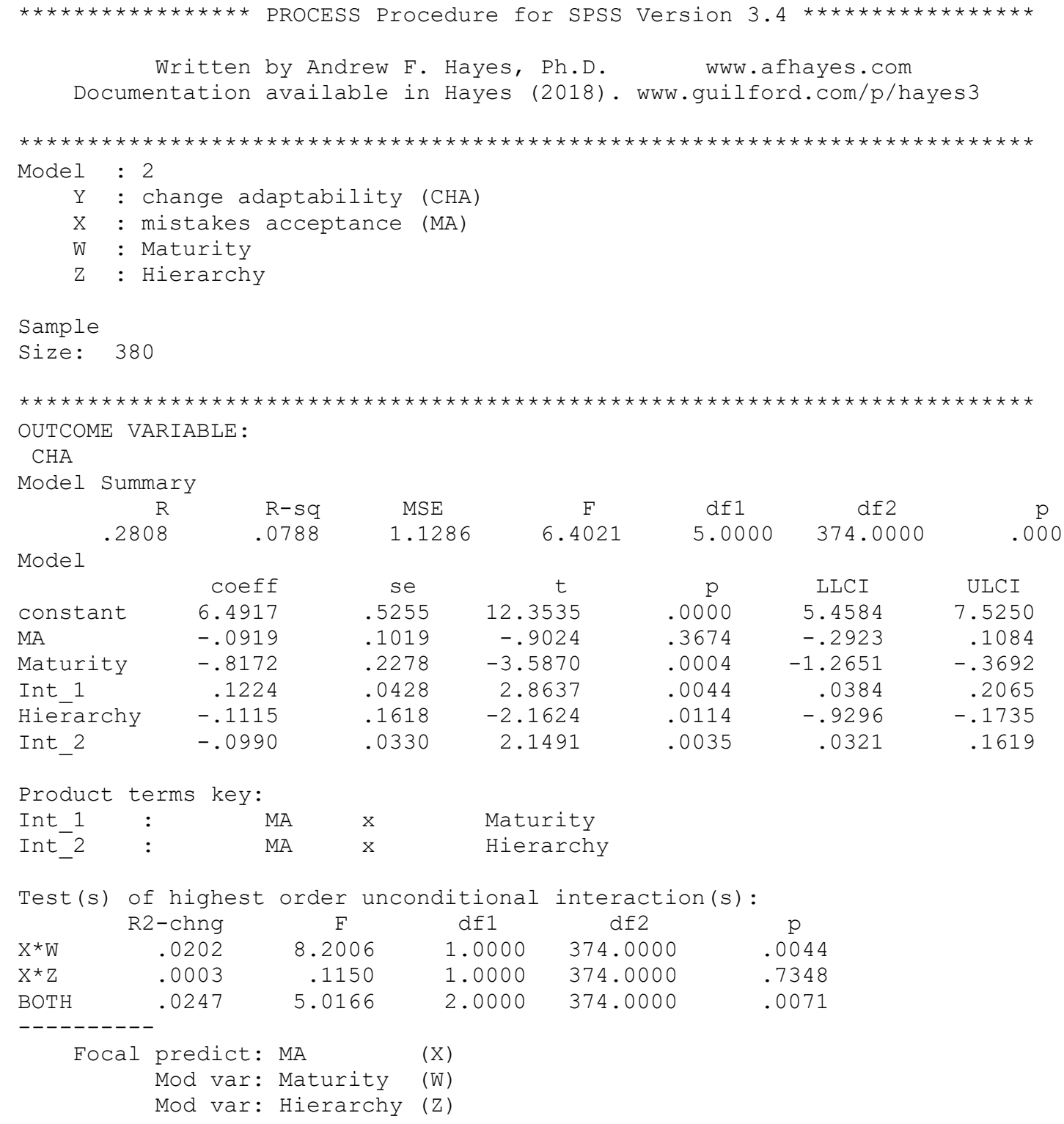

Conditional effects of the focal predictor at values of the moderator(s):

\begin{tabular}{|c|c|c|c|c|c|c|c|}
\hline Maturity & Hierarchy & Effect & $\mathrm{se}$ & $t$ & $\mathrm{p}$ & LLCI & ULCI \\
\hline low & low & .0019 & .0534 & .0351 & .9720 & -.1032 & .1069 \\
\hline low & medium & -.0124 & .0698 & -.1781 & .8587 & -.1496 & .1248 \\
\hline low & high & -.0267 & .1022 & -.2616 & .7938 & -.2277 & .1742 \\
\hline medium & low & .1243 & .0432 & 2.8769 & .0042 & .0393 & .209 \\
\hline medium & medium & .1100 & .0447 & 2.4596 & .0144 & .0221 & .197 \\
\hline medium & high & .0957 & .0755 & 1.2683 & .2055 & -.0527 & .244 \\
\hline high & low & .2467 & .0673 & 3.6635 & .0003 & .1143 & .379 \\
\hline high & medium & .2324 & .0528 & 4.4027 & .0000 & .1286 & \\
\hline high & high & .2181 & .0678 & 3.2167 & .0014 & .0848 & \\
\hline
\end{tabular}

Level of confidence for all confidence intervals in output:

95.0000

W, Z values in conditional tables are the 16th, 50th, and 84 th percentiles. ----- END MATRIX ----- 